\title{
Technology Enhanced Vocabulary Acquisition \& Listening Comprehension: A Quantitative Study of Technology- based Instruction vs. Traditional Instruction
}

Dr.Ahmad Ali Aromaih

Qassim University 


\section{Introduction}

This paper is a quantitative study that focuses on investigating the influence of the integration of technology into language instruction for students studying at the intensive course at the Departments of English \& Translation at Qassim University in Saudi Arabia. The study uses technology-based language instruction medium called "That's Life" vs. normal traditional instruction that is mainly based on lecturing. The study uses control groups, experimental groups, pre test and post tests, and delayed tests. The participants of this study are sixty students enrolled for one semester of intensive English at Qassim University. The study will use SPSS 13 for the statistical analysis of the data. The course of teaching for this study is a complete semester (i.e. sixteen weeks). The paper looks into studying the effect of technology integration into two main language arts (i.e. vocabulary acquisition and listening comprehension).

Results of this study are shared with decision makers at Department of English \& Translation at Qassim University. Expected outcome of this study is foreseen to affect methodologies of language teaching, particularly for newly admitted students to the programs of English in 
Saudi Arabia. At the bigger scale, results of this study are expected to help improve language teaching in Saudi Arabia, particularly at a time when many doubts are raised against the effectiveness of English teaching in the Kingdom. The researcher wants to thank the Deanship of Scientific Research at Qassim University for their grant to support this research.

\section{Study Problem and Aim}

The problem of this study comes from the fact that doubts, about effectiveness of language teaching in Saudi Arabia, are being raised at both lower and higher levels. One important factor behind this lack of proper language teaching lays in the methodologies of language instruction. The researcher believes that a big boost for the uplifting of language instruction can be achieved through the integration of technology into the curriculum. Successful integration of technology dictates that technology should NOT be added to the already busy curriculum but it should be integrated into it where students can see its benefit without perceiving it as an extra part to their courses. The study looks into investigating proper ways toward appropriate integration of technology for the 
development of language instruction at departments of English.

Outcome of this study should clear some misconceptions about the integration and use of technology in language instruction; the different approaches toward the use of technology in foreign language instruction at a variety of universities and it should contribute to the current debates in academia about the use of multimedia technologies in language teaching. The study will give enough evidence that weak outcomes of language instruction can be to great extent attributed to the way language is instructed. The researcher thinks it is extremely important to unveil the importance of technology integration into language instruction through using means of quantitative research.

The aim of this study can simply be directed toward the preparation of the new methods of language instruction and to support and promote the use of technology in language instruction in the named departments and also in other related departments at other universities in Saudi Arabia. The paper aims at reviewing and evaluating the current use and development of technology as it relates to the instruction of English 
language. It is important to assess the current pedagogical and technical issues being used at the three designated universities as well as other similar universities.

Outcome of this paper is expected to promote more advanced language instruction in academia in general and to facilitate the integration and promotion of technology into the language curriculum in Saudi Arabia. This research will serve as the basis for more to come research and investigation on the current status of technology integration and usage at university level language instruction. It will also supply an abundance of contents for more dense and related curriculum that is dependent on technology for language instruction. Nonlinearity of technology-based instruction will make it easy to provide continuous language learning for students through the use of weblogs.

Review of Related Literature

\section{Pedagogy and Technology}

The use of technology in the teaching of language has received considerable place in recent years. Though the use of technology in language learning has a long history, but its importance has recently been realized. 
Technology can be a catalyst in language learning as it has great prospective to herald a new vision to learn a language. It caters for the need of all kinds of students ranging from the dullest to the smartest. In addition, the variety of activities, chance to proceed with one's own speed, highly sophisticated and effective learning systems have further highlighted the need of technological advancement in the field of language teaching.

The current study focuses on the two aspects of use of technology in language teaching: technology and pedagogy. As technology changes rapidly, hence the technological innovations that affect the language teaching and learning are internet and multimedia computing. These are recent advances in the filed of language teaching.

As far as pedagogy is concerned, a shift has been noticed toward the use of technological applications in language teaching (Chapelle, 1997, 2001; Salaberry, 2001). Integration of technology has to be accompanied with appropriate teaching methodologies in order to secure effective use of technology applications. 
Uses and Effectiveness of Technologies in Language Education

Research has shown that the use of technologies in language education has proved to be extraordinarily useful in the provision of access to linguistic and cultural materials; greater opportunities to communicate in target language; easy feedback and learner motivation. Marshall (2002), while discussing the impact of technology on the effectiveness of learning, argued in favor of educational technology claiming that it "complements what a great teacher does naturally," He further believed that, "with ever-expanding content and technology choices, from video to multimedia to the Internet," educators can see that, "there's an unprecedented need to understand the recipe for success, which involves the learner, the teacher, the content, and the environment in which technology is used".

Access to authentic learning materials in an efficient way is one of the difficult areas for the second language learners. Digital multi-media technologies have made it considerably easier. Technologies help the learners to approach authentic material in less time and make process much more comfortable (Hanson Smith, 1999, Thorton \& Dudely, 1996). The use of Interactive Video disc (IVD) reduced the time span for language acquisition significantly (Shea, 2000). Another study ( Nutta, 1998) indicated that the language retention of a group of 
students in a traditional classroom was far less than the group that used multimedia computer programs. Teaching language through technologies especially by using world wide web and computer technologies has many distinct advantages that are not only related to language teaching but also work as a tool to prepare learners for today's IT world. Web technology has become a vital part of the social structure of today's world where learners can learn through e-mails and virtual communities (Wang, 2005).

It is important to mention that the use of technology is not meant, by any means, to replace actual teaching, but it is meant to be a supplement for instructors and a support for what is called in the field as a blended teaching (MacDonald, 2008)

\section{Enhancing Authenticity Using Video and Internet}

The use of video material and internet bring authenticity to language teaching. The learners can easily access the authentic material such as authentic news and literature in the target language. They can also appreciate the changes in the target language that take place on daily basis. The printed material can be static as compared to the video and internet material (Hanson-Smith, 1999; Herron, Cole, Corrie \& Dubreil, 1999; Lee, 1998). The use of video material enhanced the listening comprehension and oral production of the learners far better than the learners who didn't use video material (Weyers, 1999). 
Technology and Development of L 2 Skills

Many research studies have concluded that the use of technology enormously develops L 2 skills. On the other hand, some studies reported that computer could not contribute more to the development of productive skills such as speaking (Fleta et al., 1999). In view of such studies, efforts were made to develop collaborative learning abilities and written and oral skills by using other modes, such as Web quest and e-mails. (Goodwin - Jones, 2004). In order to enhance the written competence of the learners, web based tools such as e-mails, Internet Chat Relay, Web-chat and MSN are put in place (Stockwell \& Harrington, 2003; Wan, 2004). It was reported that the written communication in these cases was up to the desired level. Oral competence was also tested by using audio conferencing tools. It was found very effective and encouraging. (Hampel \& Hauck, 2004; Hampel and Baber, 2003).

Wang (2004) suggested oral-visual interaction that proved one of the best online interaction mode. Its importance lie in the provision of authentic learning environment where language learners can interact with each other orally and visually in a way that is much the 
same as in face to face interaction. Such studies have, therefore, proved the validity of CALL in language learning. Most recently, there has been a shift from learner-computer interaction towards learner-learner interactions. This trend very much is an evidence of CALL holding a central place in the development of L2 skills. Other research looked into the possibility for mobile technology to support language learning such as speaking (Kukulska-Hulme, 2005), vocabulary (Thornton \& Houser, 2005), phrases (Thornton \& Houser, 2005; Morita, 2003), and grammar (Sung, Huang, \& Chang, 2006)

Technology and Transmission of Cultural Knowledge

Language is now widely considered a tool to transmit the cultural knowledge of the target language to the learners. So, the cultural knowledge is occupying a reasonable place in language learning. The use of audiovideo tapes, CD-ROMs, e-mails, internet and audio-visual conferencing have greatly helped the professionals and teachers to transmit the culture of the target language to the learners. The transmission of cultural knowledge, then, helps the learners to appreciate the social phenomena within the target culture. It also improves 
their communication in negotiation and interaction with others (Warschauer, 2001; Hertel, 2003; Wan, 2004)

Hypotheses

i) Students' listening comprehension is noticeably improved if technology enhanced instructional methodologies are used.

ii) Students' vocabulary acquisition is noticeably improved if technology enhanced instructional methodologies are used.

iii) The study anticipated that the students' retention of the lesson content will be longer if technology enhanced instruction is used.

\section{Procedure}

\section{Methodology}

Study Design: The study used 84 participants who were randomly assigned into two groups i.e. experimental group and control group. The study utilized Isaac and Michael, 1995 tool of 'randomized control-group pretest post test design' The population of this study were the students at the intensive course which prepared students for the English \& Translation department at Qassim University. Before students are officially admitted to the 
English Department, they should pass a one semester course of intensive English. Number of students registered for the intensive course was 88. These students are randomly assigned into two sections. The study used section one for control group and section two for experimental group.

In the first week of the semester students are placed in queue of the two sections. They were given the permission to switch to the other section only during the first week of the semester. All participating students were Saudi male students just finishing their twelfth grade and starting their college.

\section{Material}

\section{Department Placement Test}

The study used the English Department placement test at Qassim University to figure out the participants' level of English. The results of the placement test were a part of the analysis to determine participants' language acquisition. 


\section{Lesson Content}

Ten reading passages were used for experimental and control groups. The ten passages were given to the groups in two different formats. For traditional reading instruction, passages were written down followed by some reading comprehension exercises, listening drills and vocabulary acquisition exercises. For technology enhanced instruction, an instructional software was used. The software was "That's Life" The same ten passages were presented to the experimental group. The presentation of the passages was as follows:

Four main categories were used; "Home and work", "Free Time", "Health and Emergencies", and "Around the World",. Each of these categories included nine passages. Students listened to the passage first before they were given the chance to read it. To check students' comprehension for the passage, a group of yes/ no questions was given to them.

Students' aptitude was further checked by giving them multipurpose exercises from the program. These exercises included conversation drills, spelling checks, word recognition, grammatical structures, and speaking and pronunciation practice. 


\section{Orientation and Pilot}

During the semester that preceded the semester when the study was conducted, the researcher administered a pilot study. One passage was taught to the two small groups of students i.e. eight students each. Though, it was not possible to draw statistically significant difference between the two groups, the pilot study was helpful to find out some important hurdles, like making sure that students' computer proficiency is good enough to use technology.

Study Administration and Supervision

One hundred minutes were allotted to each group twice a week. The control groups met in a traditional classroom setup. The experimental group, on the other hand, met in the language computer lab where every student had a computer, a pair of speakers, a microphone and headphones. The computer lab was also equipped with multimedia projector and eight units of stereo speakers.

Study tests

In order to check the students' level of English, the researcher accessed the students' results in their 
placement test. The aim for this step was to make sure that students' levels of language proficiency are somehow comparable to each other. The study used six tests; pretest, midtest1, 2,3, posttest, and delayed test.

i)Pretest: The aim for the pretest was to examine the students' proficiency level for the lesson content. The test was designed to cover the content material aimed for the study. The test was designed to include four parts: a reading passage followed by some comprehension questions, grammatical problems, listening comprehension tasks, and some lexical items' drills.

ii)Mid-tests: The study utilized three midtests, midtest-1, midtest-2 and midtest-3. These mid tests were four weeks apart from each other. The aim of these tests was to measure students' improvement in both control and experimental groups. The design of these tests was the same but the content was different according to the material covered. The design was basically in resemblance to the pretest. Each of the midtests covered what was taught during a five week time span.

iii) Post-test:

This test was administered at the end of the study period i.e. during the fourteenth week of the study). The 
post test was different from midtest- 3 in the fact that it examined all content material covered until fourteenth week. The nature of the posttest was basically the same as of midtest as far as the layout of the tests was concerned.

iv) Delayed test:

The students who participated in both experimental and control groups were asked to take the delayed test. The aim of this test was to gauge students' retention of the material content. The specimen of the tests resembled the posttest but the content material was altered. The test was administered three months after the study ended.

\section{Computer Proficiency Test:}

Before the study was conducted, computer proficiency test was given to all participants. The highest score was 95 out of 100 and lowest was 25 out of 100 . Any student who scored less then 50 was denied participation in the experimental group. Only six students scored less then 50 percent. They were randomly replaced by students from control group who scored more than 50 percent. 


\section{Treatment}

Both control and experimental groups were given the same treatment as far as the content material was concerned. However, the presentation and methods of delivery were different.

\section{Control treatment}

The content material was presented in traditional instruction methodologies. All content material in " That's Life" was converted into text format. The listening content was reproduced by non-native speakers of English.

\section{Experimental Treatment}

The lesson content of the experimental group was presented through computer software i.e. "That's Life" program. Content delivery was done through the main computer language lab and the data show in the lab. The audio of the program was projected to the students via the computer lab stereo speakers. The students' screens showed the same thing as the teacher's screen. Teaching was done during allocated class time. Computer lab was equipped with the software program and it was available for the students between 8:00 am to 6:00 pm. Students were given the advice to purchase the software program 
for their individual use. Few students reported that they possessed the software program.

Students were directed to use the help of media center at the college in case they had any technical difficulties or questions. The software was easy to use and the participants didn't have any problems using it.

\section{Testing the Hypotheses}

The hypotheses of this study were tested at .05 level of significance. The data of this study was statistically analyzed through SPSS 13.0. Hypotheses one, and two were tested using the following measurements:

Table 1. Descriptive Statistics for the Control Group

\begin{tabular}{llllll}
\hline Tests & No & Minimum & Maximum & M & SD \\
\hline Placement Test & 42 & 21 & 74 & 35.17 & 10.82 \\
Pretest & 41 & 9 & 55 & 27.68 & 9.44 \\
Mid-test One & 42 & 18 & 67 & 31.49 & 9.88 \\
Mid-test Two & 39 & 21 & 65 & 40.42 & 14.62 \\
Mid-test Three & 42 & 30 & 60 & 43.08 & 14.99 \\
Posttest & 40 & 31 & 62 & 41.66 & 16.13 \\
\hline Delayed Posttest & 37 & 29 & 57 & 37.93 & 13.19 \\
\hline
\end{tabular}


Table 2. Descriptive Statistics for the Experimental Group

\begin{tabular}{llllll}
\hline \multicolumn{1}{|c}{ Test } & No & Minimum & Maximum & M & SD \\
\hline Placement Test & 42 & 19 & 78 & 31.88 & 12.84 \\
\hline Pretest & 39 & 8 & 57 & 29.95 & 10.45 \\
\hline Mid-test One & 42 & 23 & 71 & 47.76 & 14.78 \\
\hline Mid-test Two & 40 & 29 & 78 & 56.48 & 17.09 \\
\hline Mid-test Three & 42 & 34 & 85 & 69.62 & 19.35 \\
\hline Posttest & 41 & 38 & 93 & 78.49 & 24.82 \\
\hline Delayed Posttest & 39 & 34 & 88 & 74.72 & 21.66 \\
\hline
\end{tabular}

Hypothesis one:

Students' vocabulary acquisition will noticeably improve if technology enhanced instructional methodologies are used.

In order to test the acceptance of hypotheses one and two, a MANOVA test was run to examine whether dependant variables, in control and experimental groups (i.e. difference between mean score of Pretest, Mid-test One, Mid-test Two, Mid-test Three, Posttest, and Delayed Posttest), affect the covariate (i.e. placement test). 
Box's test of equality of covariance matrices indicates that there is homogeneous variances at the level of $F=3.491$ and $p=.028$. MANOVA results are reported in tables $3 \&$ 4.

Table3. Multiple Analysis of Variance of Acquisition of Vocabulary with Placement Test (PT) as Covariate \begin{tabular}{lllll}
\hline Effect & Value & $F$ & Hypothesis df & $P$
\end{tabular}

\begin{tabular}{lllll}
\hline GR Wilks' Lambda & 0.829 & 3.491 & 2.010 & $.028 *$ \\
\hline${ }^{*} \mathbf{p}<.05$ & & & & \\
\hline
\end{tabular}

Wilks' lambda is at 0.829 shows that there is a statistically significant difference for multivariate test. The values of $F=3.49$ and $p=0.28$ indicates that there is a statistically significant difference between the control group and the experimental group on the dependent variables. 
Table4. Test of between Subjects Effects for Acquisition of Vocabulary with Placement Test (PT) as Covariate

\begin{tabular}{llllll}
\hline $\begin{array}{l}\text { Source } \\
\text { Dependant }\end{array}$ & SS & Df & MS & F & P \\
Variable & & & & & \\
& & & & & \\
\end{tabular}

\begin{tabular}{llllll}
\hline $\begin{array}{l}\text { Experimental } \\
\text { Group }\end{array}$ & 26.711 & 4 & 26.711 & 4.701 & $0.33^{*}$ \\
Pre-test & 58.674 & 51 & 58.674 & & \\
Post-test & & & & & \\
Control Group & & & & & \\
Pre-test & 24.191 & 2 & 16.229 & 6.618 & $0.44^{*}$ \\
Post-test & 53.316 & 50 & 12.190 & & \\
\hline$* p<.05$ & & & & & \\
\hline
\end{tabular}

Statistical data in Table 4 with $F=$ at the level of 4.701 and a $p$ value of 0.33 for the experimental group and $F=6.618$ and a $p=0.44$ for the control group show that there is statistically significant difference between experimental and control groups regarding each of the separate dependent variables (i.e. pretest and posttest). 
Hypothesis Two:

Students' listening comprehension will noticeably improve if technology enhanced instructional methodologies are used

In order to test the acceptance of hypotheses two, a MANOVA test was run to examine whether dependant variables, in control and experimental groups (i.e. difference between mean score of Pretest, Mid-test One, Mid-test Two, Mid-test Three, Posttest, and Delayed Posttest), affect the covariate (i.e. placement test).

Box's test of equality of covariance matrices indicates that there is homogeneous variances at the level of $F=\mathbf{2 . 8 3 1}$ and $p=.046$. MANOVA results are reported in tables 5 \& 6. 
Table 5. Multiple Analysis of Variance of listening comprehension with Placement Test (PT) as

Covariate.

\begin{tabular}{lllll}
\hline Effect & Value & F & Hypothesis df & P \\
& & & & \\
\hline GR Wilks' Lambda & $\mathbf{0 . 7 6 2}$ & $\mathbf{2 . 8 3 1}$ & 2.284 & $.046^{*}$ \\
& & & & \\
\hline$* \mathbf{p}<.05$ & & & & \\
\end{tabular}

Wilks' lambda is at 0.762 shows that there is a statistically significant difference for multivariate test. The values of $\mathbf{F}$ $=2.831$ and $p=0.46$ indicates that there is a statistically significant difference between the control group and the experimental group on the dependent variables.

Table 6. Test of between Subjects Effects for listening comprehension with Placement Test (PT) as Covariate

\begin{tabular}{llllll}
\hline $\begin{array}{l}\text { Source } \\
\text { Dependant } \\
\text { Variable }\end{array}$ & SS & Df & MS & F & P \\
\hline $\begin{array}{l}\text { Experimental } \\
\text { Group }\end{array}$ & 22.473 & 5 & 22.473 & 5.321 & $0.49 *$ \\
Pre-test & 54.473 & 51 & 54.473 & & \\
Post-test & & & & & \\
Control Group & & & & & \\
Pre-test & 22.191 & 3 & 26.311 & 3.527 & \\
Post-test & 241.316 & 39 & 16.238 & & $0.39 *$ \\
\hline$*$ p $<.05$ & & & & & \\
\hline
\end{tabular}


Statistical data in Table 6 with $F=$ at the level of 5.321 and a p value of 0.49 for the experimental group and $F=3.527$ and a $p=0.39$ for the control group show that there is statistically significant difference between experimental and control groups regarding each of the separate dependent variables (i.e. pretest and posttest).

Hypothesis Three:

The study anticipated that the students' retention of the lesson content will be longer if technology enhanced instruction is used

Retention of the lesson content is determined by comparing the results of the posttest and delayed tests for both groups. It is easy to notice that participants in the experimental group scored higher than those in the control group. Table 7 gives a summary of the number of correct answers for both posttest and delayed posttest. 
Table 7. Number of Correct Answers for both Groups in Posttest and Delayed Posttest.

\begin{tabular}{|c|c|c|c|c|c|c|}
\hline Test & & Posttest & & Del: & ayed Postt & \\
\hline & Overall & Control & Experimental & Overall & Control & Experimental \\
\hline Q1. & 80 & 24 & 36 & 76 & 17 & 28 \\
\hline Q2. & 80 & 23 & 32 & 74 & 17 & 25 \\
\hline Q2. & 80 & 25 & 32 & 76 & 16 & 31 \\
\hline Q3. & 80 & 21 & 33 & 76 & 24 & 31 \\
\hline Q4. & 80 & 18 & 28 & 76 & 24 & 32 \\
\hline Q5. & 79 & 19 & 28 & 76 & 20 & 28 \\
\hline Q6. & 80 & 23 & 37 & 73 & 18 & 32 \\
\hline Q7. & 78 & 25 & 34 & 74 & 17 & 32 \\
\hline Q8. & 79 & 20 & 30 & 75 & 18 & 25 \\
\hline Q9. & 80 & 32 & 38 & 76 & 21 & 32 \\
\hline Q10. & 80 & 29 & 35 & 76 & 20 & 34 \\
\hline Q11. & 80 & 28 & 37 & 76 & 22 & 30 \\
\hline Q12. & 78 & 19 & 31 & 76 & 22 & 28 \\
\hline Q13. & 79 & 27 & 31 & 76 & 23 & 26 \\
\hline Q14. & 77 & 14 & 23 & 76 & 16 & 31 \\
\hline Q15. & 80 & 21 & 34 & 76 & 17 & 30 \\
\hline Q16. & 80 & 24 & 33 & 76 & 18 & 29 \\
\hline Q17. & 79 & 21 & 35 & 75 & 15 & 29 \\
\hline Q18. & 80 & 27 & 36 & 75 & 25 & 26 \\
\hline Q19. & 79 & 24 & 36 & 74 & 19 & 27 \\
\hline Q20. & 80 & 34 & 37 & 75 & 30 & 30 \\
\hline
\end{tabular}


Table 8 presents numbers and mean of correct answers for the control and experimental groups on both posttest and delayed posttests. These numbers are shown in the following table.

Table 8. Mean of Correct Answers for both Groups in Posttest and Delayed Posttest.

\begin{tabular}{|c|c|c|c|c|c|c|c|}
\hline & Con & & & Expe & iimen & & \\
\hline Type of Post Test & $\mathbf{X} 1$ & n1 & Mean & $\mathrm{X} 2$ & n2 & Mean & $\mathbf{z}$ \\
\hline Post Test & 498 & 788 & 24.90 & 696 & 788 & 34.80 & $2.10 *$ \\
\hline $\begin{array}{l}\text { Delayed Post } \\
\text { Test }\end{array}$ & 419 & 703 & 20.95 & 616 & 703 & 30.80 & $2.17 *$ \\
\hline
\end{tabular}

A $z$ test was used and results of the test indicate that there is a statistical significant difference between the two groups in their posttest and delayed posttest scores. The mean of the participants' answers indicates that experimental group (34.80 and 30.80) scored higher than the control group (24.90 and 20.95). 


\section{Discussion}

It seems to be possible now to draw some conclusions and make some judgments based on the analysis of the statistical data of this study. There was a significant difference between the experimental and the control groups in terms of their reading competence and listening comprehension. This leads us to accept the first two hypothesis of this study suggesting that students' reading competence and listening comprehension is noticeably improved when technology is used compared to the traditional teaching of the control group.

Vocabulary acquisition for technology based instruction was also improved and statistical significant difference between the two groups was found. Students' retention of the lesson content was noticeably longer for the experimental group leading us to accept the last two hypothesis of this study.

Although, this paper was meant to test the hypothesis of this study, yet it has documented and observed some interesting findings such as; (1) students in the control group felt less advantaged to see their colleagues in the experimental group exposed to various methods of learning and to use computers and software, 
(2) students in the experimental group felt more privileged to see that they were participating in somehow new environment for them, (3) the experimental group showed eagerness to learn and motivation to work on their own more than the control group, (4) it is important to mention that all significant differences between the two groups were not only due to the introduction of technology in language learning, but to the fact that unless technology introduction is accompanied by change in methodology especially in teachers' and students' roles. Teachers should not be the only source of knowledge and students should not be only recipient of information. It is crucial that teachers change their role to be guides and facilitators and students change their role to be finders and explorers.

Although, only three teachers participated in this study for only a period of fifteen weeks, it is safe to say their perception in teaching both groups was different. Teachers pointed out that their work with the experimental group was in many aspects different from that of the control group. Teacher "A", for example, mentioned that students in the experimental group were more motivated and they took their learning outside the walls of the classroom. They, in many times, came to class with new things that they learned either from the software 
or from the Internet. Teacher "B" also mentioned that students in the experimental group paid more attention to the way they pronounce English. They always try to "speak like them", he said. Teacher "C" mentioned that students in the experimental group thought of their learning as an ongoing process that does not end at the end of the semester. He said that, he felt that his students always wanted to take to the next stage where they learn more about English.

\section{Conclusions, and Recommendations}

This study made an attempt to quantitatively research, explore, and test new methods and approaches in language teaching and learning based on new language authoring instructional multimedia tools. The present study was conducted in an environment where introduction of technology for language instruction is still questioned.

As, it is the nature of studies like the present one, there is always room for more research and replications particularly with alternation in the design in respects like change in the software used or change in the language skills tested or the overall environment or in the different multimedia authoring tools like the internet. 
Finally, it is the researcher's hope that findings of this study get to see its way for real application in life in terms of wide-spreading the use of technology-based language instruction. It is also vital that further research, in areas related to technology use for language instruction within the context of Saudi Arabian institutions, is conducted. 


\section{References}

Chapelle, C. A. (1997). CALL in the Year 2000: Still in Search of Research Paradigms. Language Learning and Technology, 1(1), 19-43.

Chapelle, C. A. (2001). Computer Applications in Second Language Acquisition: Foundations for Teaching, Testing, and Research. Cambridge: Cambridge University Press.

Egbert and E Hanson-Smith, 1999. CALL environments: research, practice, and critical issues, TESOL, Alexandria, VA

Fleta et al., 1999: Evaluating Multimedia Programs for Language Learning: A case study, RECALL 11(3)

Hampel, R., \& Baber, E (2003). Using internet based audiograpyhic and video conferencing for language learning. In U.Flix (Ed). Language Learning Online toward best practices

Hampel, R., Hauck, M. (2004). Toward an effective use of audio conferencing in distance language courses. Language Learning and Technology, 8(1)

Herron, C., Cole, S. P., Corrie, C., \& Dubreil, S. (1999). The effectiveness of video-based curriculum in teaching culture. The Modern Language Journal..

Hertal , T.J (2003). Using an email exchange to promote cultural learning. Foreign Language Annals., 36(3)

Kukulska-Hulme, A. (2005). The mobile language learner-now and in the future. Fran Vision till Praktik. 
Language Learning Symposium, Umea University, Sweden. Retrieved November 30, 2006, from http://www2.humlab.umu.se/symposium2005/program.ht m.

MacDonald, J. (2008). Blended learning and online tutoring: Planning learner support and activity design (Second Edition). Burlington, VT: Gower.

Marshall, P. (2002). Voice recognition: Sound technology. Federal Computer Week.

Morita, M. (2003). The Mobile-based Learning (MBL) in Japan. Proceedings of the First Conference on Creating, Connecting and Collaborating through Computing. Retrieved December 28, 2005, from http://csdl2.computer.org/comp/proceedings/c5/2003/1975/ 00/19750128.pdf.

Nutta, J. (1998). Is computer-based grammar instruction as effective as teacher-directed grammar instruction for teaching L2 structures?. CALICO Journal, 16 (1), 49- 62.

Salaberry, M. R. (2001). The Use of Technology for Second Language Learning and Teaching: A Retrospective. The Modern Language Journal, 85(1), 39-56

Shea, P. (2000). Leveling the Playing Field: A Study of Captioned Interactive Video for Second Language Learning. Journal of Educational Computing Research, 22(3), 243263. 
Stockwell, G. and Harrington, M. (2003) The incidental development of L2 proficiency in NS-NNS email interactions. CALICO Journal 20 (2)

Sung, Y. T., Huang, C. C., \& Chang, K. E. (2006). The design and application of a mobile devices-based real time formative assessment system. Paper presented at the IADIS International Conference Mobile Learning, July, 13-16, Dublin.

Thornton, P., \& Houser, C. (2005). Using mobile phones in English education in Japan. Journal of Computer Assisted Learning, 21(3), 217-228.

Wan, SEL (2004). Second Language Socialization in Bilingual Chartroom. Global and Local Consideration. Language and Learning Technology, 8(3)

Wang, M. J., Shen, R.M., \& Tong, R. (2005). Mobile learning with cell phones and Pocket PCs. Lecture Notes in Computer Science, in R. Lau, Q. Li., R. Cheung, \& W. Liu (Eds), Proceedings of the 4th International Conference on Web-Based Learning (ICWL), Hong Kong, 3583, 332-342. (Indexed by Science Citation Index).

Warscyhouer, M (2001). Online communication. In R. Carter \& D. Nunan (Eds). The Cambridge Guide to Teaching English to speakers of other Language. CUP.

Weyers, J.R. (1999). The effect of authentic video on communicative competence. The Modern Language Journal. 83 (3) , 339-349. 